\title{
CANSAT MINI-SATELLITE PROJECT, TEST PROCEDURE AND MISSION IMPLEMENTATION
}

\author{
M. Ostaszewski ${ }^{*}$, K. Dzierżek ${ }^{* *}$
}

\begin{abstract}
The only limitation for human curiosity is our technological advancement. History has thought us that space exploration is one of the most significant driving force of human development. One of the means to explore the universe are artificial satellites. They can perform tasks unachievable for us. Construction of the satellite is very complicated and time-consuming process. Fortunately, several classes of satellites are distinguished. Entry level one-CanSat has similar dimensions to an ordinary soda can. The main subject of this paper is the construction of these type of satellites. Then all testing procedure and every part of the mission is described. At the end of the paper conclusions and suggestions for further development are expressed.
\end{abstract}

\section{Keywords: minisatellite, CanSat, rocket}

\section{Introduction}

The new space race has begun. This time it is somehow different. Nefarious aspirations of two superpowers do not drive it. Humankind's curiosity inspires the race. Today's people see space the same way as our ancestors saw oceans- vast "oceans" of possibilities and places waiting to be explored. The race is also not orchestrated by the space agencies. They play an equal role in the development of spaceera systems. Private companies such as SpaceX or Blue Origin, with budgets of millions of dollars, develop, i.e. reusable propulsion systems or whole habitats ready to be settled on another planet's surface. The vision of space exploration drives dreams and aspirations of the next generation, to push boundaries of science and engineering for the wellbeing of humankind, many of them will pursue STEM careers in the future. In order to prepare those students for future challenges, numerous competitions in various fields of space exploration are held yearly all around the world.

NASA frequently holds competitions for students from K-2 up to college, to inspire and sometimes prepare participants for future employment in the space sector. The Mars Society is an organiser of University Rover Challenge. The team of students has to build, program and test a Mars rover in the Martian-like environment. Several designs find their usage in the form of spin-off technologies or inspire their creators to develop science with their contributions (Czaplicki et al., 2016).

Every year in many countries CanSat competitions are held. The idea behind those challenges is to simulate satellite mission. Students have to design, build, test and participate in a mission of a satellite of their design. Each competition has set of rules and requirements that those teams have to meet in order to score points and win. Among most popular tasks to perform during each mission are telemetry transmission during flight, storage of collected data for further analysis, remote control of selected mission's aspect, landing in a designated place etc. Every satellite also has to fit strict budget limit, usually 500 euro. The mission is a good test field for students' ideas, that not only combines different disciplines but is also, and predominantly, literal "rocket science".

Mgr inż. Michał Ostaszewski, Bialystok University of Technology, Faculty of Mechanical Engineering, m.ostaszewski22@gmail.com

** Dr hab. inż. Kazimierz Dzierżek, Bialystok University of Technology, Faculty of Mechanical Engineering, k.dzierzek@pb.edu.pl 


\section{The design}

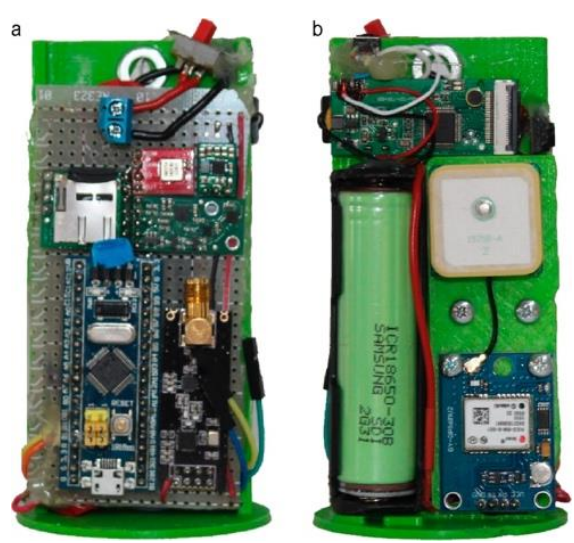

Fig. 1: CanSat

The CanSat, which was designed by the authors, complies with basic rules of the competitions. To achieve this goal, the device had to be very compact to fit within limited space (cylinder $\mathrm{H}$ : $115 \mathrm{~mm} \mathrm{~d}: 66 \mathrm{~mm}$ ). An array of sensors had to be chosen, the system also required reliable yet light and compact power source. All internal apparatus had to be encased in a resilient core.

Core's structure

The core was designed using CAD software (SolidWorks). The basic shape was determined by CanSat rules, based on this, a lightweight yet durable structure was modelled. The internal core has to provide shielding of all internal components as well as allow the equipment to measure different parameters of the mission. Several aspects of the mission had to be taken under consideration as well such as: withstanding release of the satellite (performed with a small explosive), ability to endure lift-off overloads or eliminating the risk of moisture intrusion after landing in bodies of water. Careful simulations were performed using built-in software (SW Simulation) to obtain final design. The core was fabricated using 3D technology using ABS plastic further processed to increase its durability (Fig. 1, a. front, b. back).

\section{Onboard systems}

The onboard consists of sensors array and the main computer that collects input data saves it in storage and transmits readings as long as possible (Antunes, 2015). Sensors used in our system have to collect telemetry data for flight analysis. As so we decided to implement sensors depicted in Fig 2: a. GPS module, c. accelerometer, c. IMU.

GPS module (GY-NEO6MV2) was precalibrated and tested, resulting in $\sim 4 \mathrm{~m}$ accuracy. This level of precision is adequate for the use case, considering more precise modules

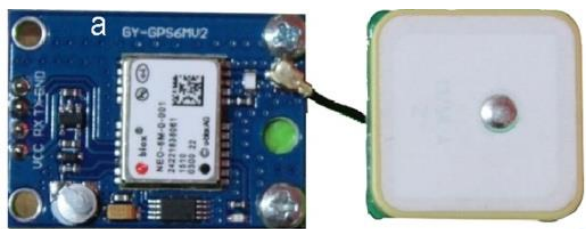

C

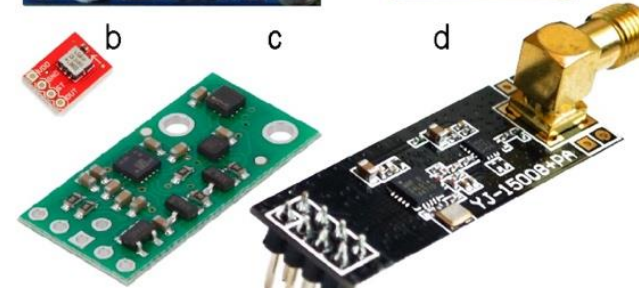

Fig. 2: Electronic components

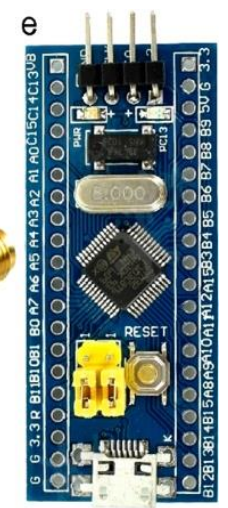

cost significantly more. The standalone accelerometer (SparkFun's ADXL193) was added to improve measurement precision in Z-axis (up movement), also to prevent losing data due to lift-off damage of IMU. The Inertial Measurement Unit (Altimu-10v5) consists of 3 subsystems: integrated six axes accelerometer with gyroscope (LSM6DS33), magnetometer (LIS3MDL) and barometer (LPS25H). Data form subsystems are used to obtain all necessary data during mission's telemetry like altitude, speed and acceleration in all three axes and Euler's angles of the satellite.

The data was read, collected, processed, transmitted and stored using an onboard computer (Fig. 2, e.). It is based on ARM STM32F103C8T6 Cortex-M3 able to perform those operations very quick, also requiring very little power to do so. The last element of the system is radio module (nRF24L01+ PA LNA $2,4 \mathrm{GHz}$, Fig. 2, d.). It allowed us to monitor the first phase of the flight as well as to find the satellite after landing. Tested operation range of the device is $750 \mathrm{~m}$, which fulfilled our needs.

\section{The rocket}

To ascend the satellite, a rocket is required. During the preparation phase, several tests were performed, thanks to helping of Polish Rocket Society (PTR). First, five experiments were performed using small rocket made of PVC. The tests were to scale (10Ns

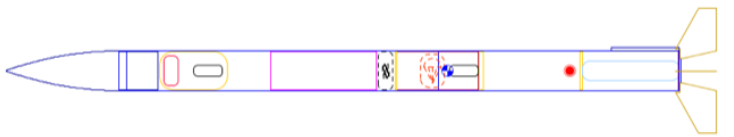

Fig. 3: Rocket designed in OpenRocket of thrust), to master lift of procedure and learn how to prepare the mission while still on the ground (Westfield, 2014; Węgrzyn, 1963). All attempts were successful, that encouraged us to move to the bigger rockets. Next three attempts were failures due to unfavourable thrust to mass ratio caused by using the 
same engines. While increasing outer diameter of the rocket (from $16 \mathrm{~mm}$ to $40 \mathrm{~mm}$ ). Thanks to the cooperation with PTR in a simulation software (OpenRocket) a third design was created (Fig. 3). Rocket length extended up to $1,5 \mathrm{~m}$ and the engine was changed to a Wessex model (Speedline) with 290Ns of thrust. All flights performed using this setup were successful.

The last element of the rocket is a release mechanism(UWS). It is a small explosive that is stetted off when of axis tilt of the rocket is detected. Rocket stages part, allowing a satellite to continue its journey on its own, while stages return safely to the ground on parachutes.

In addition to the rocket system, a ground control station was developed. It consisted of a personal computer with a software precisely designed to collect data transmitted form the satellite and control mission parameters, in addition, the setup was equipped with devices enabling monitoring of surrounding airspace and recording mission's run, proven useful during UAV tests (Walendziuk et al., 2017).

\section{System tests.}

The onboard system assembly was pre-tested. To do so, we decided to use the tallest building on the campus- students' dormitory. It has ten storeys that give almost $30 \mathrm{~m}$ height difference, adequate to test sensors' performance and durability of the satellite. The probe was thrown through the window and descended on parachutes. The altitude measurement, obtained by fusing data from barometer and acceleration's second integral is shown in figure 4.

The line graph depicts ascension to the $10^{\text {th }}$ floor using a lift, followed by an altitude stabilisation and vertical drop during descending. The second attempt followed immediately, this time climbing a flight of stairs, clearly visible between the $90^{\text {th }}$ and $140^{\text {th }}$ second of the trial. During the test, all systems operated as intended, so it was a time to simulate the mission.

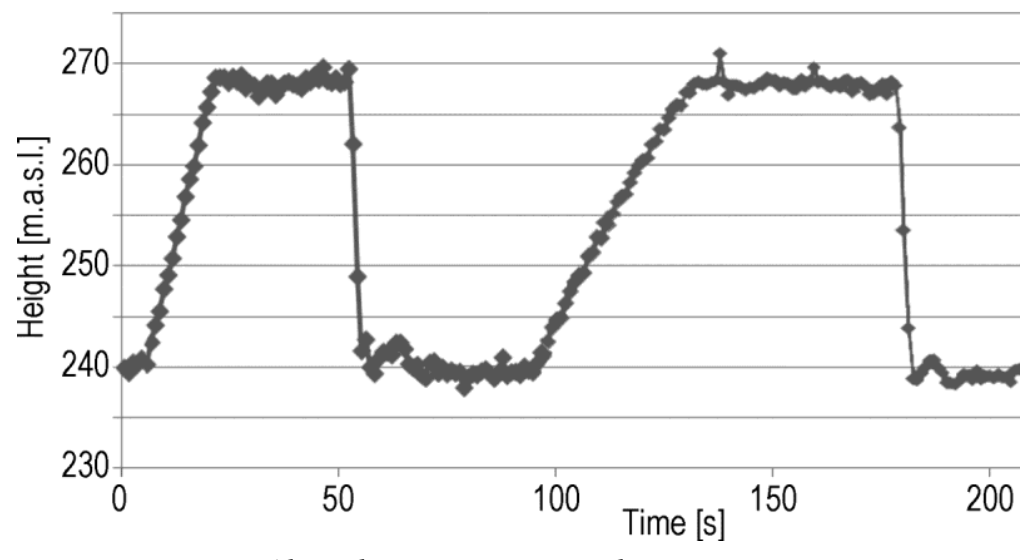

Fig. 4: Altitude measurement during system tests

\section{The simulated mission.}

The mission took place on December 2nd, 2017 near Bialystok. The mission had five stages. The preparations for a lift-off including arming a rocket and setting up a ground control station was supervised by PTR representative. The second stage was lift-off. It was achieved utilising remote ignition mechanism. Third stage- ascension and reaching apogee came after exhaustion of the rocket's fuel the satellite was released using UWS device. Following this stage, the mission came info fourth one- falling on parachutes. The satellite and the rocket fallen on separate ones to allow uninterrupted data collection. The fifth stage- landing marked the last stage of the mission.

The data gathered during ascension, apogee and landing was both stored safely on an internal drive and transmitted to the ground control as long as the rocket was within transmission range. Gathered information was used to analyse the mission and draw conclusions toward further development of the project.

\section{Data analysis.}

The analysis started with collected data recovery. Fortunately, all systems worked during the whole mission and gathered useful information about the flight. First, we would like to discuss the flight's altitude, it was expressed in relation to the ground base. Shown in a Fig. 5, one can see all stages of the mission. In $0 \mathrm{~s}$ the ignition is initiated. The ascension lasted 6 seconds reaching apogee at the altitude of $390 \mathrm{~m}$. At this point, the rocket was separated and satellite released. Between $6^{\text {th }}$ and $7^{\text {th }}$ second, the satellite had free fallen until parachutes fully opened. The CanSat descended on parachutes for the next $39 \mathrm{~s}$ landing safely on the $45^{\text {th }}$ second. The ascension speed varied, reaching $110 \mathrm{~m} / \mathrm{s}$ maximum. The 
descent was slow and calm at about 9,2 $\mathrm{m} / \mathrm{s}$. Analyzing the acceleration data, one can also see all mission stages. However, it also gives us information about flight phases and slightly rough landing.

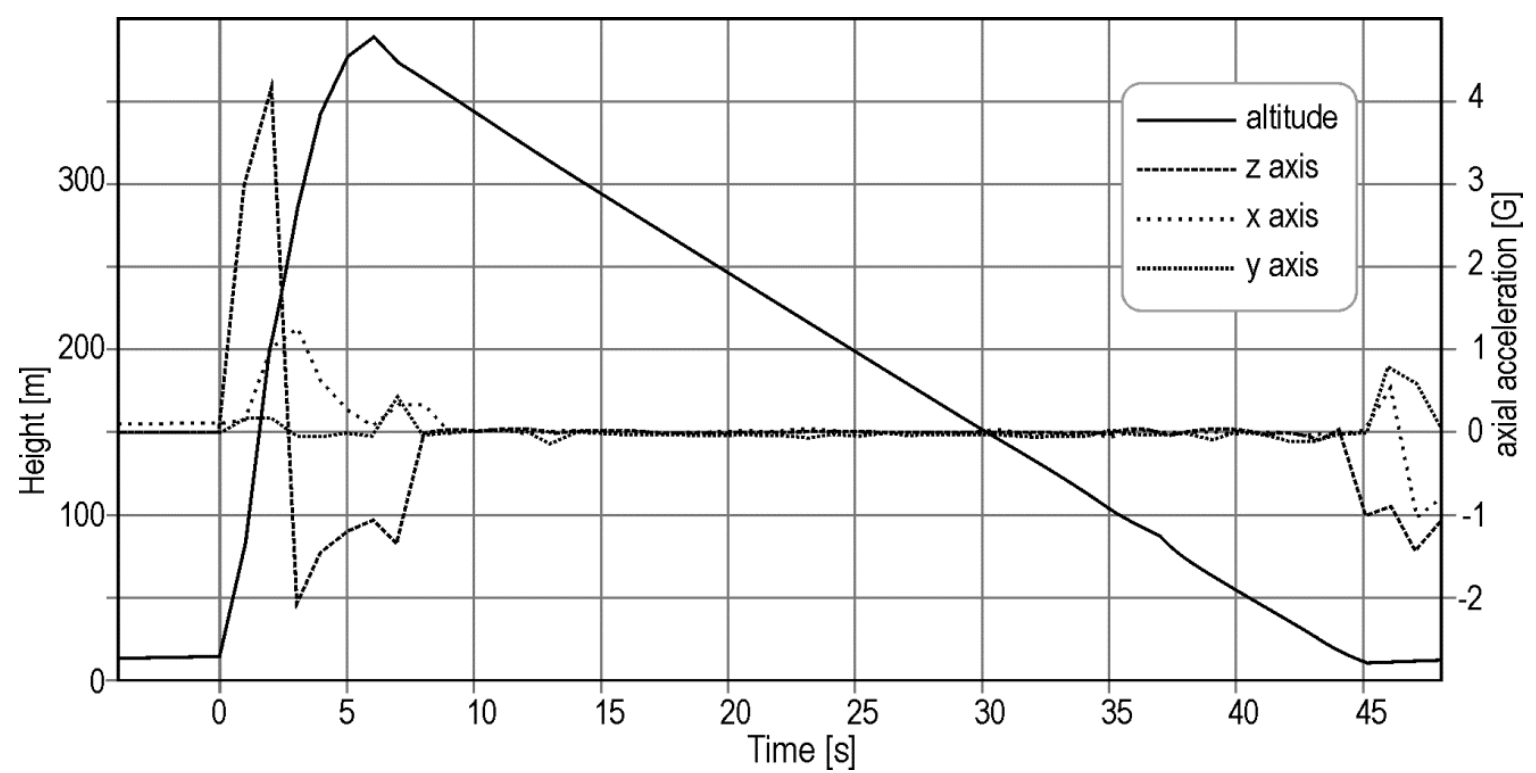

Fig. 5: Altitude and acceleration during mission

The rocket was ascending for $2 \mathrm{~s}$ until the engine exhausted the fuel. Driven by the momentum, it climbed up. However, the acceleration changed its sense. Between $3^{\text {rd }}$ and $6^{\text {th }}$ second, the acceleration changed its sense once more until the rocket reached its apogee. This fluctuation is related to the release mechanism and opening the parachute. From the $8^{\text {th }}$ second until $44^{\text {th }}$ CanSat was freefalling, and hit the ground fluctuating the acceleration once more.

Collection of these data lead to a conclusion that the separation and release of the satellite came before reaching the apogee, as so it is required to fine-tune the UWS prior future missions.

\section{Conclusions}

Not everything went as planned during at our CanSat mission. Unfortunately, before start GPS module was physically damaged and did not work. At the mission, we reached an apogee of almost $400 \mathrm{~m}$. At this moment we are analysing collected data. The meticulous testing process increases the chances of mission success. In our opinion mission was a success. Almost every module of CanSat worked correctly. The knowledge gained by testing process and lunch sequence gave us the ability to make many corrections in future construction.

\section{Acknowledgement}

Authors would like to express the deepest gratitude to the Polish Rocket Society for providing assistance during rocket build and lift-off preparations.

\section{References (style - Reference Chapter EM 2017)}

Czaplicki, P., Rećko, M. and Tołstoj-Sienkiewicz, J. (2016) Robotic Arm Control System for Mars Rover Analogue, in: Proc. 21st International Conference on Methods and Models in Automation and Robotics (MMAR), Międzyzdroje, pp. 1122-1126, DOI: 10.1109/MMAR.2016.7575295.

Antunes, S. (2015) DIY Comms and Control for Amateur Space, San Francisco.

Walendziuk, W., Ołdziej, D., Bińczyk, D.P. and Słowik, M. (2017) Ground Control Station software design for Micro Aerial Vehicles, in: Photonics Applications in Astronomy, Communications, Industry, and High Energy Physics Experiments 2017 (eds. Romaniuk, R.S. Linczuk, M.), Warsaw University of Technology, pp. 1-9, DOI: $10.1117 / 12.2280934$.

Westerfield, M. (2014) Make:Rockets. Down-to-Earth Rocket Science, Sebastopol.

Węgrzyn, B. (1963) Rocket models, Ministry of Defence Press, Warsaw (in Polish). 